\title{
Endocarditis Infective, CTCAE
}

National Cancer Institute

\section{Source}

National Cancer Institute. Endocarditis Infective, CTCAE. NCI Thesaurus. Code C143441.

A disorder characterized by an infectious process involving the endocardial layer of the heart. 